\title{
Structural biomimetics in soft synthetic composite materials: A proof-of-concept alginate-polyamide soft hierarchical composite
}

\author{
M. Sharabi* , H. D. Wagner \\ Department of Materials and Interfaces, Weizmann Institute of Science, Rehovot 76100, Israel
}

Received 6 October 2020; accepted in revised form 8 February 2021

\begin{abstract}
Natural materials often consist of hierarchical architectures, which are extremely efficient in mechanical terms. Whereas the structure-function relationship is well-studied in natural hard materials, soft materials are not getting equal attention, despite their high prevalence in nature. These soft materials are usually constructed as fiber-reinforced composites consisting of diverse structural motifs that result in an overall unique mechanical behavior. In this study, as a proof-of-concept, a soft biomimetic composite was fabricated from a hierarchical electrospun polyamide fiber, reinforcing a hydrogel matrix and creating a simple synthetic analog for natural soft composites. This material system investigates the structure-function relationship between the structure and mechanical function by mimicking different structural motifs. The polyamide-hydrogel composite exhibited large deformations and nonlinear material behavior. Varying degrees of crimping enabled a controlled strain stiffening behavior and engineered transition from matrix-dominated to fiber-dominated behavior. We also observed that the individual nanofibers in our bundles created cross-bridges with the matrix and within the bundle, making the material system more resistant to failure. Our bio-inspired composite demonstrated mechanical behaviors similar to natural soft composites, which can aid in the future design and development of the next generation of soft architectural composites.
\end{abstract}

Keywords: biopolymers, biomimetics, soft composite materials, mechanical properties, structure-function relationship

\section{Introduction}

Natural materials are characterized by highly efficient structures, which have evolved over many years [1-11]. They are constructed as multi-level composites made from relatively simple building blocks and consist of inherent structural motifs that result in remarkable mechanical properties $[1,6,12]$. Natural composite materials can be categorized as hard or soft materials. Typically, hard materials combine inorganic and organic components and are characterized as strong and tough materials with linear elastic mechanical behavior in small strains. The biomimetics of these materials has been the focus of many studies [13-16]. Although biomimetic analogs of soft natural materials are not as widespread, they have lately attracted increasing attention [3, 8, 17-19]. Natural soft composites, such as soft tissues, are extremely efficient under tension because they are generally constructed as fiber-reinforced materials. In general, soft tissues are built as different combinations of repeated and simple building blocks with different mechanical functions, such as collagen, proteoglycans, and elastin. The collagen fibers act as reinforcement [20], the proteoglycans serve as a binder and provide an aqueous environment, and the elastin is responsible for the flexibility of the tissue [21]. Besides, different structural motifs at different length scales create various soft tissue structures and functions using the same simple building blocks [21]. Despite the broad diversity and versatility in soft tissues, they 
all share a similar strain stiffening regime (J-shaped behavior) with large deformations. For example, in tendons, mechanical behavior is divided into the toe, heel, and linear regions. In the toe region (the initial part of the stress-strain curve,) small stress is needed to create a large deformation $[22,23]$. In this region, the crimp of the fibrils is straightened, and the proteoglycan matrix governs the mechanical behavior. In the heal and linear regions, the collagen fibers dominate the mechanical behavior, and stiffening occurs [24]. In the linear region, the proteoglycans enable a gliding mechanism between the fibers due to their hydrated nature $[22,23,25,26]$.

The influence of fiber volume fraction (FVF) and orientation on soft synthetic composites have been investigated (mainly for tissue engineering applications [27-31]) and found to affect different mechanical properties such as strength, stiffness, and ultimate strains. Apart from the FVF and fiber orientation, additional structural motifs are present in soft tissues, such as fiber crimping [32-34], sacrificial cross-linking (which allows fibril gliding) [23, 25], and structural hierarchy $[11,22]$. Crimped fibers were synthetically fabricated as a part of a laminate or as isolated fibers to investigate their deformation behavior [35-42].

One of the characteristic properties of natural materials is their hierarchical structure composed of several structural levels, from the nano to macro-scale, such as the fibril-fiber-fascicle assembly in tendons and ligaments.

Nanofibers can be manufactured efficiently using the electrospinning process. Electrospinning is a well known and efficient technique for creating nanofibers from a polymer solution using high-voltage, allowing large diversity in materials and structures [43-46]. These nanofibers can be assembled to create diverse nanocomposites and even biomimetic multiscaled composites [43, 46-49].

Usually, biomimetics is used to imitate natural mechanisms toward developing newly designed materials with superior properties. However, due to the high complexity and multi-functionality of natural materials (such as biological, chemical, mechanical functions, etc.), a systemic biomimetic approach can verify the different functions by an iterative reverse-engineering approach. For instance, the structural studies of hard natural composites are a good example of such a reverse-biomimetic approach in synthetic material systems $[9,11,50-55]$, and such an approach has been used to elucidate the influence of the brickand-mortar structure of the nacre on its toughness $[9,56]$.

By using reverse biomimetics principles [50, 57-59], we can gradually separate the complex structural motifs by engineering principles. Mimicking these different structural motifs and assembling them can provide a better understanding of the structure-function behavior of soft-tissues and aid in developing the next-generation of soft composite materials with tailor-designed nonlinear mechanical behavior. These novel soft composites can be applicable in many fields, such as soft robotics $[8,18]$, tissue engineering [27-30, 35, 60], and biomedical devices [3].

In this study, we fabricated a hierarchical bundle consisting of electrospun synthetic hydrophilic nanofibers and embedded it in an alginate hydrogel matrix to create a new soft composite material inspired by natural tissue structures. The objective of this study was to investigate mechanically and computationally the structure-function relationship and to control the nonlinear behavior of the material by using biomimetic structural motifs found in soft natural materials.

\section{Materials and methods}

\subsection{Fabrication}

\section{Materials}

Polycaprolactam (Nylon 6, synthetic polyamide) pellets (181110, Sigma Aldrich) were dissolved in Formic Acid (F0507, Sigma Aldrich) under stirring to obtain a $20 \mathrm{wt} \%$ solution. Sodium Alginate 10-60 (Protanal LF 10-60, FMC biopolymer, USA) was dissolved in double-distilled water (DDW) under stirring to obtain a $6 \mathrm{wt} \%$ solution. $\mathrm{CaCl}_{2}$ (1311, J.T. Baker) was dissolved in DDW to obtain a $0.1 \mathrm{M}$ solution.

\section{Electrospinning}

The electrospinning apparatus consisted of a high voltage DC power supply (FC series, Glassman high voltage, Inc.), a syringe pump (TJ-3A, Longer Precision Pump Co., Ltd), and a rotating drum collector. The rotating drum was connected to the DC motor (2150 rpm@6 V, Pololu Corporation, Las Vegas, USA) and a bench power supply (PSB-1400M, GW Instek). The drum was wrapped with grounded conductive aluminum foil. A glass syringe $(1 \mathrm{ml})$ with an $18 \mathrm{G}$ needle was connected to the syringe pump (Figure 1a). The flow rate was kept at $350 \mu \mathrm{l} / \mathrm{h}$. Electrospinning was carried out at $16 \mathrm{kV}$, and the working 


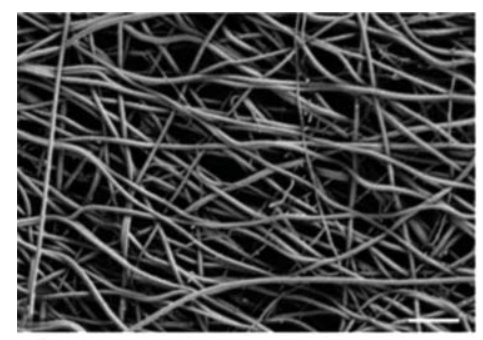

a)

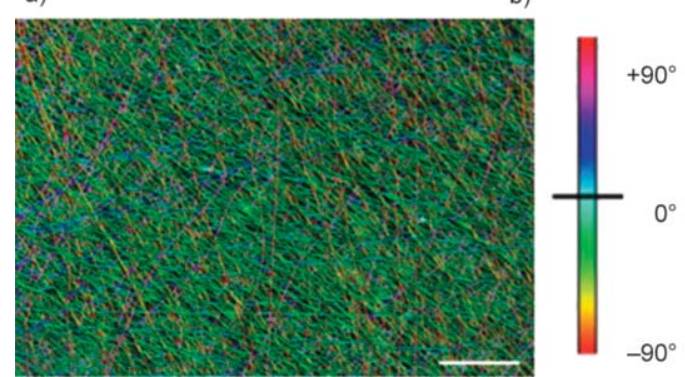

d)

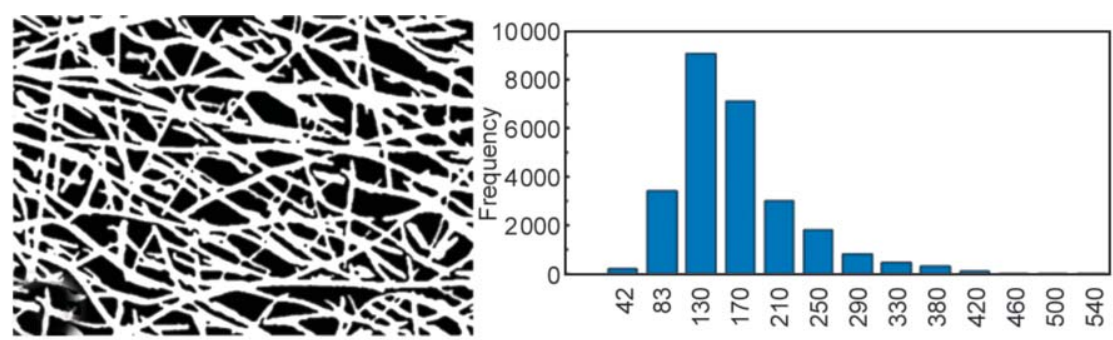

c)

Diameter [nm]

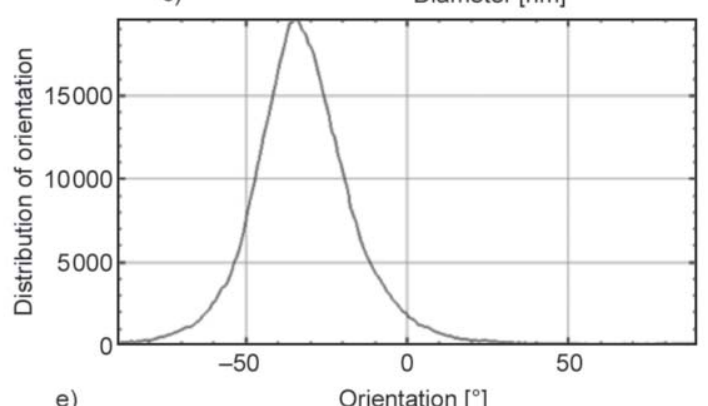

Figure 1. Diameter and orientation of electrospun polyamide nanofibers. Diameter of nanofibers: (a) SEM image (scale bar $1 \mu \mathrm{m}$ ). (b) Segmented image of the nanofibers using DiameterJ algorithm (ImageJ, NIH). (c) Diameter distribution of the nanofibers. (d) Orientation colormap of the nanofibers using OrientationJ (ImageJ, NIH) (scale bar $10 \mu \mathrm{m}$ ). (e) Distribution of orientations-the nanofibers consist of clear unidirectional alignment).

distance was $12 \mathrm{~cm}$ from the needle, to create a continuous polyamide film comprising aligned nanofibers.

\section{Bundle fabrication}

The electrospun film was removed from the drum and manually cut to a $5 \times 5 \mathrm{~cm}$ rectangular shape using an in-house razor blade apparatus. The film was removed from the aluminum foil and manually rolled in the spinning direction to create a bundle so that the nanofibers will be aligned with the longitudinal direction of the bundle.

\section{Crimping}

The bundle was inserted into a metallic mold with different crimping degrees $\left(60,90\right.$, and $\left.120^{\circ}\right)$. The mold was tightened with screws and located on top of a hot plate at $62.5^{\circ} \mathrm{C}$ ( $\mathrm{Tg}$ of Polycaprolactam) for one hour. The crimping angle was defined as the upper angle of the crimp triangle. The fiber crimp strain $\left(\varepsilon_{c}\right)$ (Equation (1) and (2)) are defined as follows:

$\varepsilon_{\mathrm{c}}=1-\frac{x}{y}=1-\sin \frac{\theta}{2}$

where:

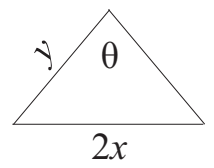

\section{Nanocrimping}

The bundle was inserted into a beaker containing DDW located on top of a hot plate at $62.5^{\circ} \mathrm{C}\left(T_{\mathrm{g}}\right)$ for one hour. The bundle was dried in $96 \%$ ethanol (Sigma Aldrich). Nanocrimping was generated at the micron level, as previously reported in [40], the DDW was used as a plasticizer and created crimping at the electrospun nanofiber level by removing the residual stresses formed during the electrospinning process.

\section{Composite fabrication}

The bundle was inserted in a silicon dog-bone shaped mold $(W=2 \mathrm{~mm}, T=1 \mathrm{~mm}, G L=15 \mathrm{~mm})$ (Figure 1b). The mold was then filled with an alginate solution ( $6 \mathrm{wt} \%$ ), which completely covered the bundle. The air bubbles were manually removed to prevent defects in the composite. The mold was covered with a dialysis cellulose membrane $(M W C O=$ 14000, D9777, Sigma- Aldrich) to allow uniform cross-linking, based on our previous works [29, 30, $61,62]$. Then, the membrane was flattened, and the mold was soaked in $\mathrm{CaCl}_{2}$ solution $(0.1 \mathrm{M})$ for $48 \mathrm{~h}$ at room temperature to enable the cross-linking of the alginate hydrogel.

(2) Fiber orientation, diameter, and bundle volume fraction

The nanofiber orientation and diameter were calculated from the SEM images of the electrospun film 
using the OrientationJ [63] and DiameterJ [64] plugins in the ImageJ software (NIH). The composite's FVF was calculated as the bundle volume divided by the total volume of the specimen, without considering its inner structure.

\subsection{Mechanical test}

The mechanical testing of alginate-polyamide composites and alginate hydrogels was carried out with a computer-controlled Rheometric Scientific Minimat tensile tester (Rheometric Scientific, Series 2000) using a $200 \mathrm{~N}$ load cell at a testing speed of $3.0 \mathrm{~mm} / \mathrm{min}$ using displacement control mode. Typical sample dimensions were $2 \mathrm{~mm}$ (width) $\times 1 \mathrm{~mm}$ (thickness) $\times 24 \mathrm{~mm}$ (length). The test was recorded using the uEye Camera (5580CP, iDS Imaging Development Systems $\mathrm{GmbH}$ ). The composites and hydrogels were inserted into the standard grips of the tensile tester and tightened to prevent sample slipping. Tensile testing of the polyamide electrospun film and bundle was carried out using an Instron 4502 with a $10 \mathrm{~N}$ load cell at a testing speed of $3.0 \mathrm{~mm} / \mathrm{min}$ in displacement control mode. The electrospun bundle and film were glued to a thin frame cut before the mechanical test to prevent buckling of the samples while inserted into the tensile machine. We used engineering stresses and strains: stresses were defined as the force divided by the initial cross-sectional area, and strains as the displacement divided by the initial gage length. The gage length was defined as the distance between the grips at zero force. Ultimate stresses and strains were defined as maximum stresses and strains, respectively. The moduli were calculated as the tangent modulus at a specific strain. Samples dimensions were measured using a digital caliper and a micrometer.

\subsection{Finite element model}

A finite element (FE) model was generated to simulate the crimping effect on the mechanical behavior of the polyamide-alginate soft composite using the Abaqus FE software (Abaqus/CAE 2016, Dassault Systems, Simulia Corp., Providence, RI, USA). The model consisted of a heterogeneous $3 \mathrm{D}$ rectangularshaped rod with a crimped, single bundle (crimping angle of $60,100,120$, and $150^{\circ}$ ). The rod was constructed using solid elements representing the alginate matrix $\left(1 \times 1 \times 10 \mathrm{~mm}^{3}\right)$. The polyamide bundle was simulated by beam elements attached between the nodes of the solid elements with 3\% FVF (B31H for
Table 1. Material properties of the composite model.

\begin{tabular}{|c|c|c|}
\hline \multicolumn{2}{|c|}{ Alginate matrix $6 \%$} & Nylon 6 bundle \\
\hline \multicolumn{2}{|c|}{ Hyperelastic - Marlow [65] } & Hyperelastic - Ogden \#3 [66] \\
\hline Strain & $\begin{array}{l}\text { Stress } \\
\text { [MPa] }\end{array}$ & Material constants \\
\hline 0 & 0.00 & $\mu_{1}=-110.32, \alpha_{1}=2.00, D_{1}=0$ \\
\hline 0.02 & 0.07 & $\mu_{2}=91.96, \alpha_{2}=4.00, D_{2}=0$ \\
\hline 0.04 & 0.09 & $\mu_{3}=103.60, \alpha_{3}=-2.00, D_{3}=0$ \\
\hline 0.06 & 0.11 & \\
\hline 0.08 & 0.12 & \\
\hline 0.10 & 0.12 & \\
\hline 0.12 & 0.14 & \\
\hline 0.14 & 0.15 & \\
\hline 0.16 & 0.18 & \\
\hline 0.18 & 0.20 & \\
\hline 0.20 & 0.21 & \\
\hline 0.22 & 0.24 & \\
\hline 0.24 & 0.27 & \\
\hline 0.26 & 0.30 & \\
\hline 0.28 & 0.33 & \\
\hline 0.30 & 0.36 & \\
\hline 0.32 & 0.39 & \\
\hline 0.34 & 0.44 & \\
\hline 0.36 & 0.47 & \\
\hline 0.38 & 0.52 & \\
\hline 0.40 & 0.55 & \\
\hline
\end{tabular}

the beam elements and C3D8H for the solid elements) $[30,31]$. The fiber volume fraction matched the experimental value.

The material properties were nonlinear and hyperelastic (i.e., the stress-strain relationship is defined as a constitutive law and derived from the strain energy density function) and described in Table 1 . The material properties were determined based on the mechanical tensile tests. The alginate matrix was homogenous and isotropic and fitted to the Marlow hyperelastic model [65]. The polyamide bundle behavior was fitted to the Ogden strain energy density function (order 3) [66]; it was assumed to be a continuous medium, and its nanostructure was not finely represented. The boundary conditions matched the mechanically tested samples of a rod under uniaxial loading with displacement control. The left plane of the rod was fixed, and the right plane was subjected to $10 \mathrm{~mm}$ displacement. The FE model employed implicit nonlinear static analysis.

\subsection{Scanning electron microscopy}

The composites were dehydrated through a series of graded ethanol agents, from a concentration of 70 to 
$100 \%$. The samples were sputtered with iridium and then investigated using a scanning electron microscope (SEM) (Carl Zeiss Sigma 500).

\subsection{Statistical analysis}

Statistical analysis was carried out with a $95 \%$ confidence interval using GraphPad Prism 7 (GraphPad Software, La Jolla, CA, USA). The mean and standard deviation (SD) were calculated for all measurements. The results with $p<0.05$ were considered as statistically significant. A non-parametric t-test (Mann-Whitney test) was used to compare the data groups.

\section{Results}

The results section demonstrates the geometry of the nanofibers, film, bundle, and composites and their mechanical properties. We tested the effect of crimping in the nanoscale on dry film and bundle and the crimping in the millimetric-scale on the composite material to understand their effect on the deformation behavior.

\subsection{Electrospinning}

The nanofiber diameter ranged between $100-300 \mathrm{~nm}$ (Figure 1a-1c). Anisotropy was observed (Figure 1d$1 \mathrm{e})$, with a distribution width alignment of $60^{\circ}$. The diameter of the bundle was $0.25 \pm 0.05 \mathrm{~mm}$.

\subsection{Composite fabrication}

Alginate-polyamide composite fabrication is shown in Figure 2. The composite was constructed as a single bundle embedded in an alginate hydrogel (Figure 2d). The average fiber volume fraction was $3 \pm 1.6 \%$. The composite dimensions were $1.66 \pm 0.31 \mathrm{~mm}^{2}$ and $12.86 \pm 1.05 \mathrm{~mm}$ for the crosssection and gage length (GL), respectively. The hydrogel matrix provided a hydrated surrounding to the electrospun bundle, and thus, the composite acted as a hydrated composite.

The dry bundle consisted of a hierarchical structure with an entangled nanostructure, as shown in Figure 3 . The resulting bundle crimping angles $(\theta)$ (Equation (2)) were 75,127 , and $145^{\circ}$, and crimp strain $\left(\varepsilon_{\mathrm{c}}\right)$ of $0.39,0.11$, and 0.05 , respectively.

The different samples that were tested are listed in Table 2. The bundle and matrix interface is shown in Figure $4 a, 4 b$, as observed by SEM. The matrix was tightly linked to the bundle and took the form of the nanofibers.

\subsection{Mechanical behavior of the composite}

The alginate-polyamide composites exhibited mechanical behavior between the behaviors of the matrix and the dry bundle (Figure 5a), thus approximately following the rule of mixtures. The mechanical behaviors for all tested samples demonstrated large

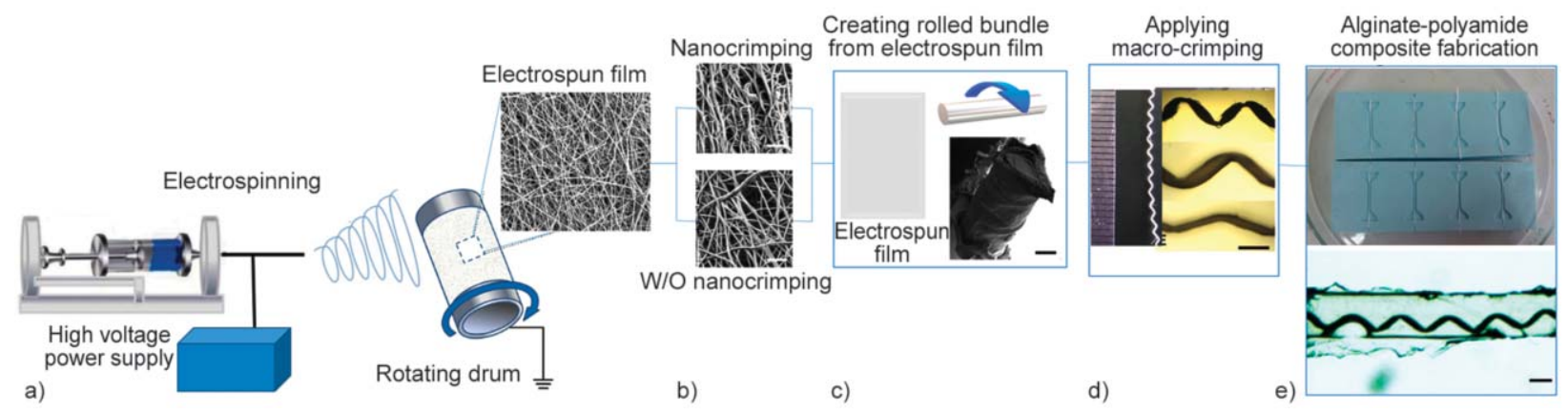

Figure 2. Hierarchical soft composite fabrication. (a) Electrospinning apparatus. (b) Adding nanocrimping to electrospun film. Scale bar $1 \mu \mathrm{m}$. (c) Rolling the electrospun film to create a bundle. Scale bar $100 \mu \mathrm{m}$. (d) Applying different bundle macro-crimping angles $\left(75,127\right.$, and $145^{\circ}$, up to bottom). Scale bar $1 \mathrm{~mm}$. (e) Alginate- polyamide composite fabrication. Scale bar $1 \mathrm{~mm}$.
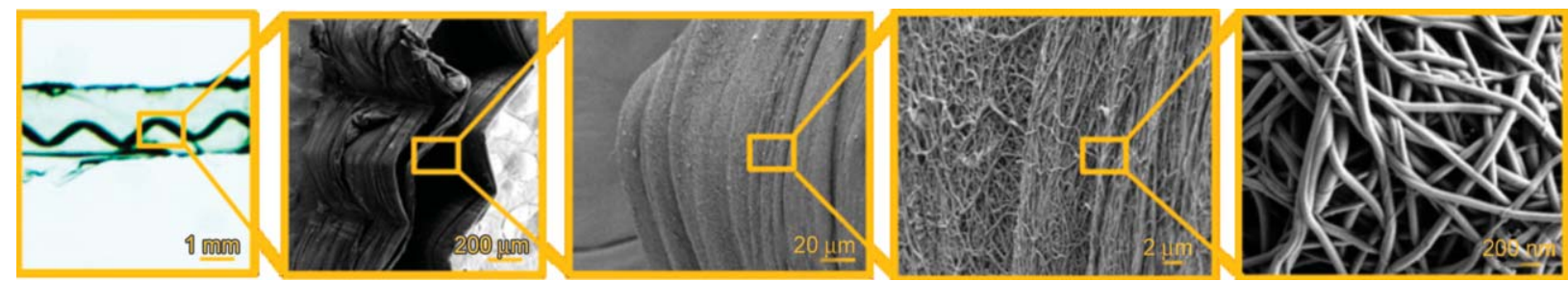

Figure 3. Hierarchical structure of crimped polyamide- alginate soft composite. Right-to-left- from electrospun nanofibers to hierarchical soft composite. 
Table 2. Geometry of the tested samples.

\begin{tabular}{|l|c|c|c|c|c|c|}
\hline & $\begin{array}{c}\text { Tested } \\
\text { samples }\end{array}$ & $\begin{array}{c}\text { Cross-section } \\
{\left[\mathbf{m m}^{\mathbf{2}}\right]}\end{array}$ & $\begin{array}{c}\text { Gage length } \\
{[\mathbf{m m}]}\end{array}$ & FVF & $\begin{array}{c}\text { UTS } \\
{[\mathbf{M P a}]}\end{array}$ & Max. strain \\
\hline Composite samples & 33 & $1.68 \pm 0.30$ & $12.83 \pm 1.08$ & $3 \pm 1.6 \%$ & - & - \\
\hline Composite crimp angle $0^{\circ}$ & 7 & $1.63 \pm 0.30$ & $13.14 \pm 0.45$ & $3 \pm 0.8 \%$ & $2.04 \pm 0.57$ & $0.38 \pm 0.06$ \\
\hline Composite crimp angle $145^{\circ}$ & 4 & $1.69 \pm 0.13$ & $13.00 \pm 0.41$ & $3 \pm 1.1 \%$ & $2.67 \pm 0.69$ & $0.38 \pm 0.04$ \\
\hline Composite crimp angle $127^{\circ}$ & 19 & $1.7 \pm 0.33$ & $12.82 \pm 1.22$ & $3 \pm 1.9 \%$ & $2.17 \pm 0.94$ & $0.39 \pm 0.07$ \\
\hline Composite crimp angle $75^{\circ}$ & 3 & $1.83 \pm 0.23$ & $12.00 \pm 1.73$ & $3 \pm 1.8 \%$ & $0.69 \pm 0.24$ & $0.37 \pm 0.06$ \\
\hline Alginate matrix & 4 & $2.57 \pm 0.26$ & $17.58 \pm 1.09$ & - & $0.48 \pm 0.11$ & $0.44 \pm 0.09$ \\
\hline Electrospun bundle & 16 & $1.32 \cdot 10^{-2} \pm 4.65 \cdot 10^{-3}$ & $5.15 \pm 0.12$ & - & $193.6 \pm 38.20$ & $0.51 \pm 0.17$ \\
\hline Electrospun film & 24 & $6.88 \cdot 10^{-2} \pm 1.65 \cdot 10^{-2}$ & $5.24 \pm 0.11$ & - & $8.5 \pm 3.30$ & $0.31 \pm 0.10$ \\
\hline
\end{tabular}

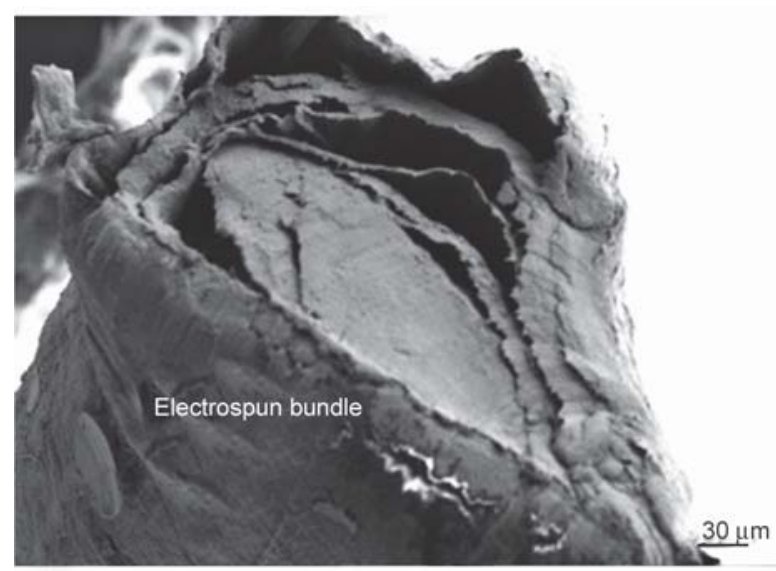

a)

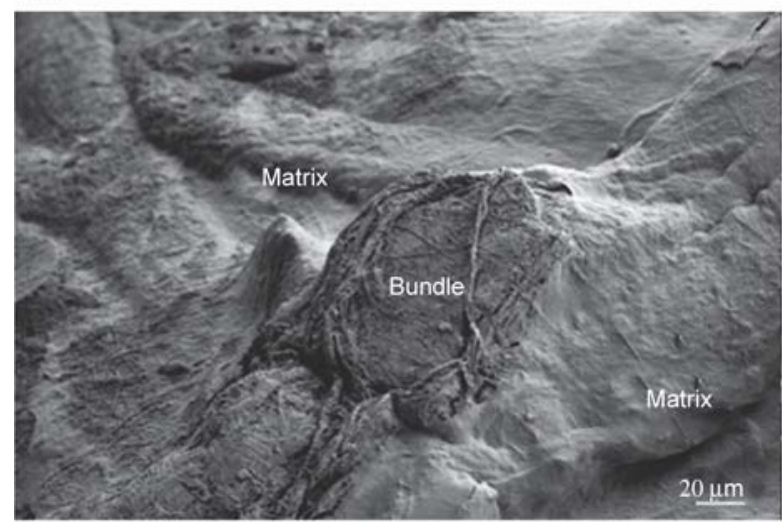

c)

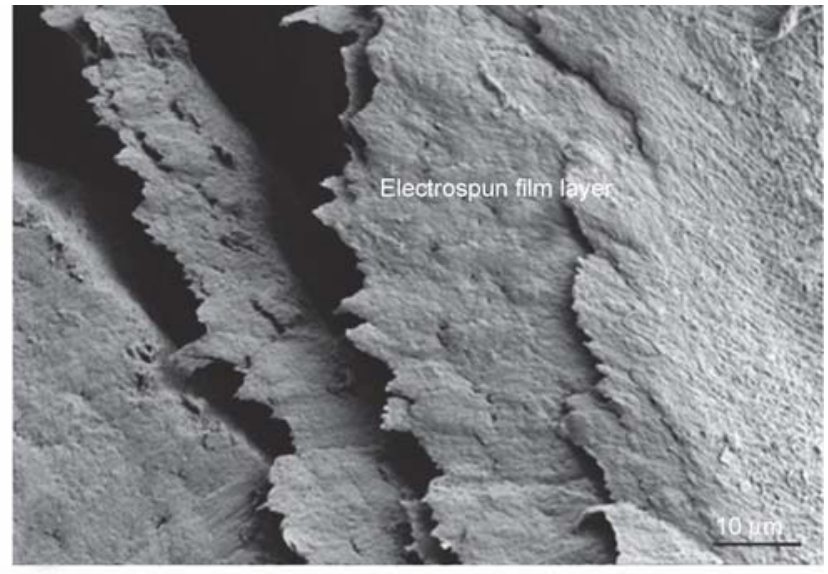

b)

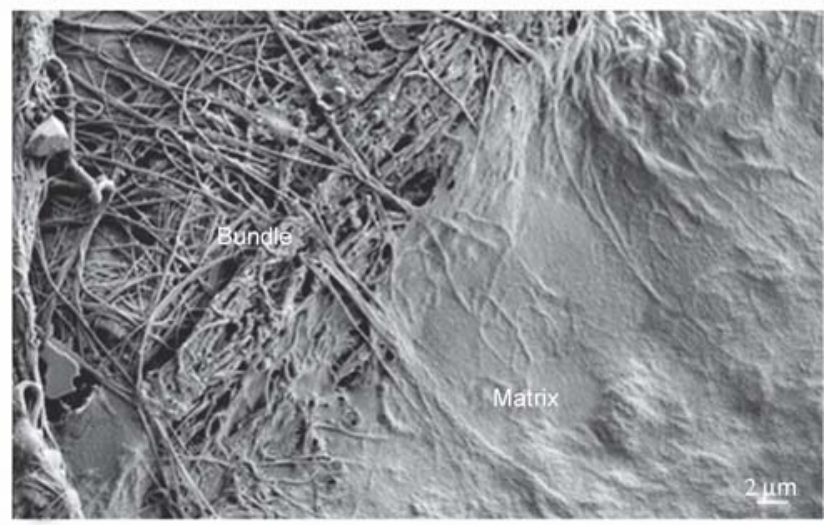

d)

Figure 4. (a, b) Polyamide bundle layers made of rolled electrospun film. (c, d) Fiber bundle-matrix interface.

deformations behavior. The addition of crimping to the bundle resulted in J-shaped behavior with strain stiffening (Figure 5).

The averaged modulus of the composite with a straight bundle $(\mathrm{FVF}=3 \%)$ was $7 \mathrm{MPa}$, which is seven times more than the matrix modulus $\left(E_{\text {matrix }}=\right.$ $1 \mathrm{MPa})$, but four times less than the film modulus $\left(E_{\mathrm{Film}}=32 \mathrm{MPa}\right)$ and 62 times less than the bundle modulus $\left(E_{\text {bundle }}=438 \mathrm{MPa}\right)$ (Figure 5a). The composite modulus was approximately half $(7 \mathrm{MPa})$ of the calculated modulus using the rule of mixtures (14 MPa).
When a force was applied to the composite with a crimped bundle, first, the crimping was straightened, and the matrix governed the initial part of the stressstrain curve (toe region), as shown in Figure $5 \mathrm{~b}$ (I) (for a composite with $127^{\circ}$ ). Then, the bundle gradually started to carry the load, and strain stiffening was observed (heel region, Figure 5b (II)). When the bundle was straightened, it carried the load, and linear behavior was seen (Figure 5b (III)) until the composite failed (Figure $5 \mathrm{~b}$ (IV)).

The composite exhibited high toughness (i.e., tearing resistance manifested in large deformations and 

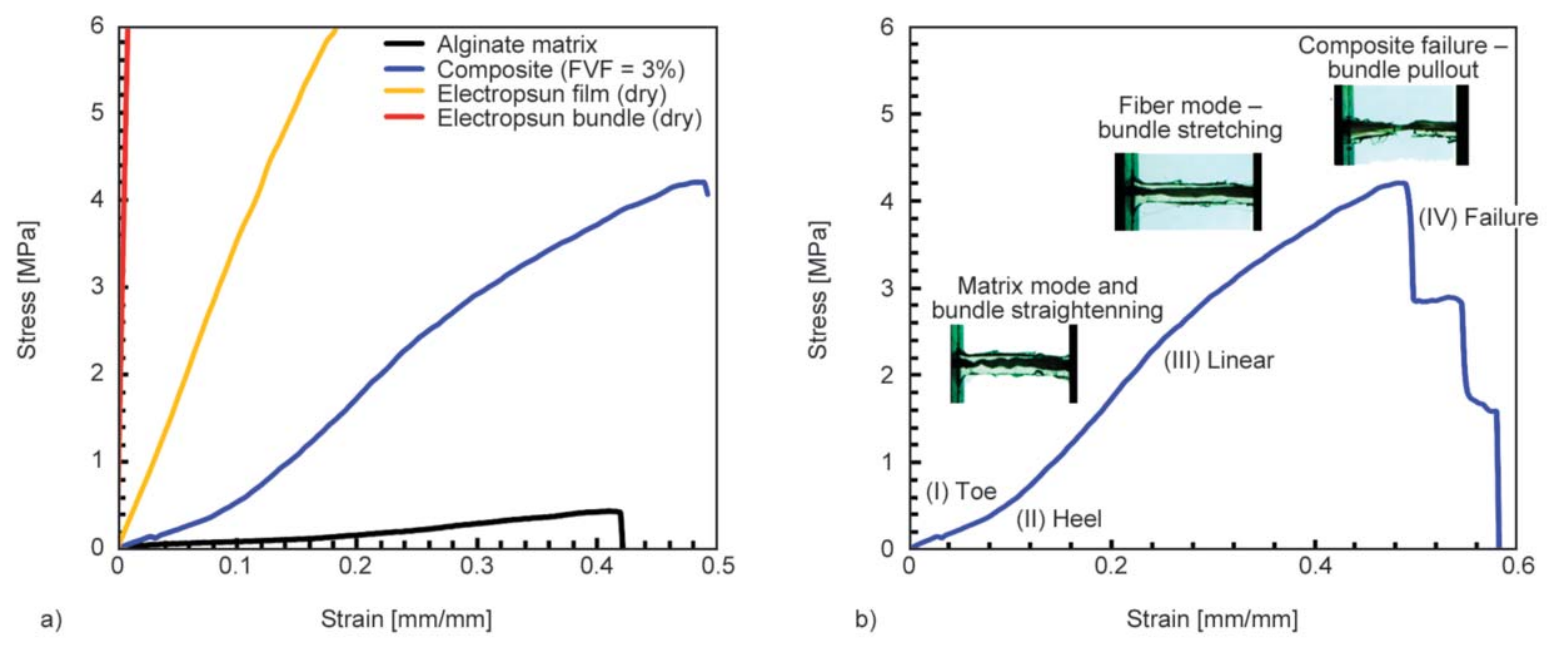

Figure 5. (a) Mechanical behavior of electrospun bundle, film, matrix, and polyamide-alginate composite (FVF 3\% and crimp angle of $127^{\circ}$ ). (b) Representative mechanical behavior of polyamide-alginate soft composite (crimp angle of $127^{\circ}$ ) with the different regions: (I) Toe, (II) Heel, (III) Linear, and (IV) Failure.

ductility [11]); however, their failure behavior varied between the different samples and did not demonstrate a clear trend. Most of the composites failed by pull-out (Figure $5 \mathrm{~b}$ and $6 \mathrm{a}, 6 \mathrm{~b}$ ), whereby the interface failed, and the bundle was pulled out

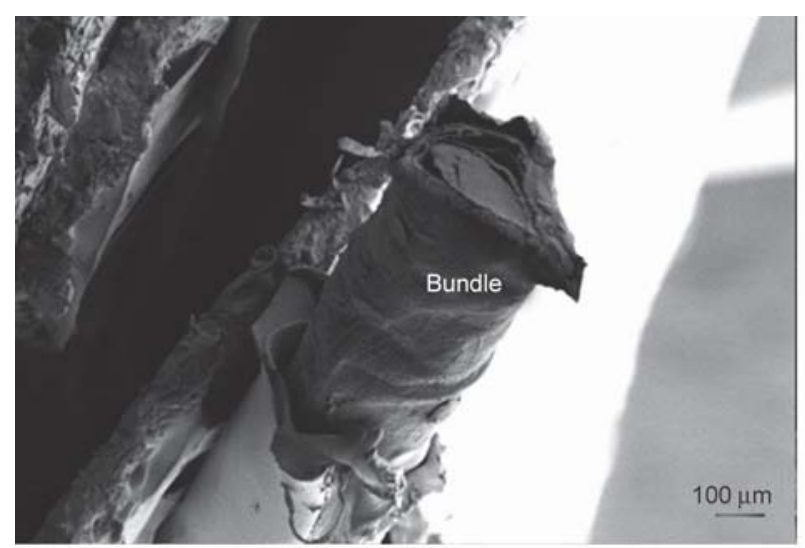

a)

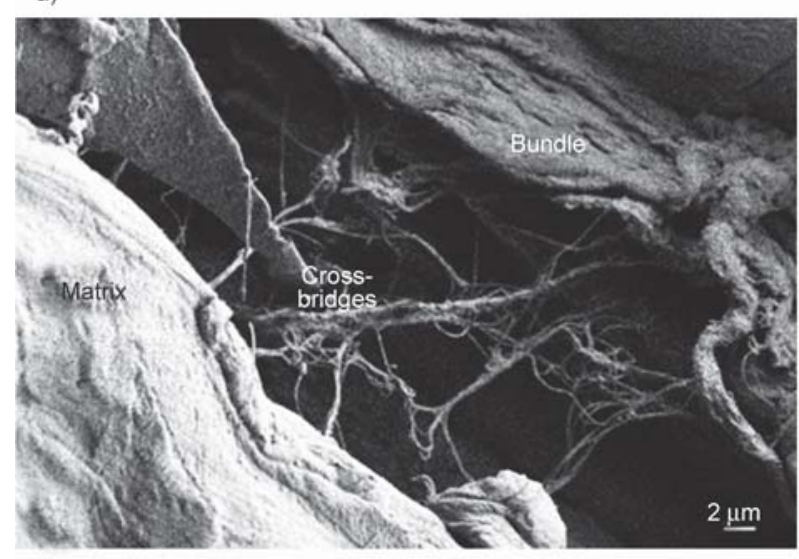

c) from the matrix until the bundle also failed. Crossbridges formed between the bundle layers in the bundle-matrix interface, as observed in the SEM images obtained after the mechanical test (Figure $6 c, 6 d)$.

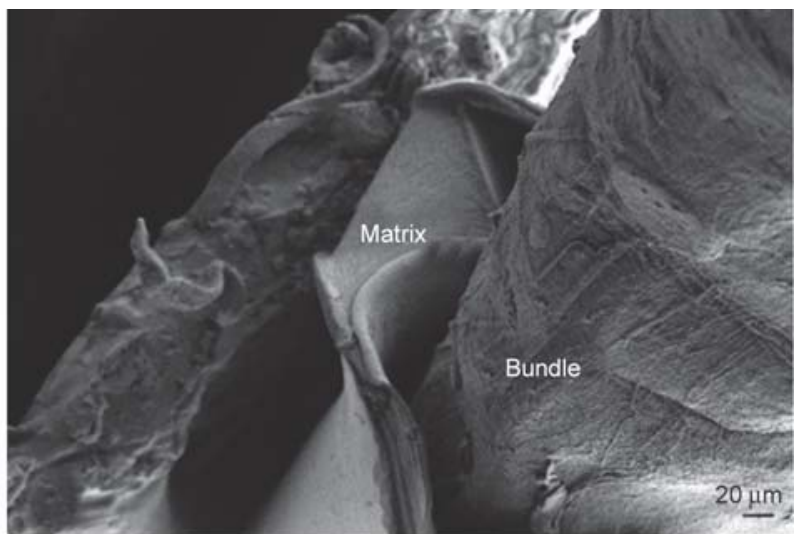

b)

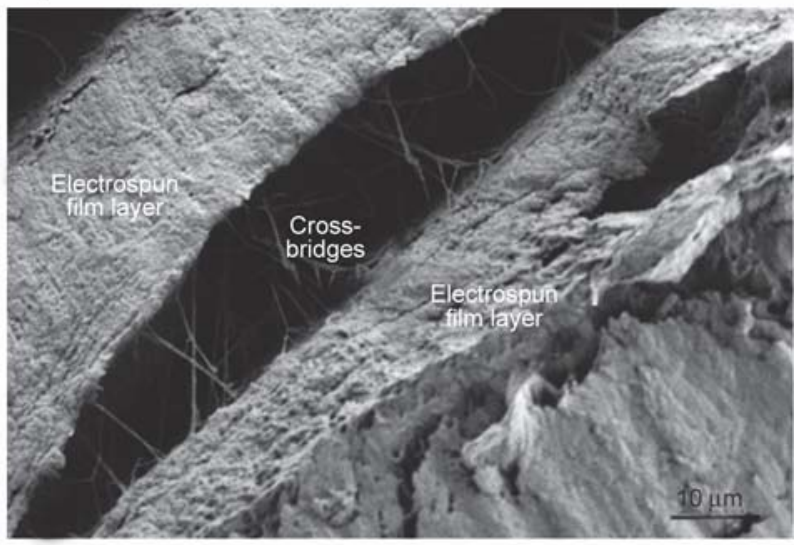

d)

Figure 6. Failure of polyamide- alginate composite. $(a, b)$ pull-out failure of the electrospun bundle. Fiber-matrix crossbridges (c). Cross-bridges between different layers of the fiber bundle (d). 


\subsection{The mechanical influence of crimping}

Straight $(n=9)$ and crimped bundle composites for the three fabricated crimping angles $(75,127$, and $145^{\circ}$, and $\varepsilon_{\mathrm{c}}=0.39,0.11$, and $0.05(n=3,19$ and 4$)$, respectively), were tested. The largest toe region was observed for $75^{\circ}$, followed by $127^{\circ}$, and then $145^{\circ}$. The toe region behavior matched the alginate matrix specimens' behavior, and stiffening occurred in the average $\varepsilon c$ strain (Figure $7 b$ ).
The tangent moduli at strains of $0.05,0.1,0.015$, and 0.2 are presented in Figure $7 \mathrm{a}$. For $\varepsilon_{\mathrm{c}}=0.39$, we cannot see the change in stiffening since it should be larger than the tested moduli. The straight bundle composite demonstrated relatively similar values for all tested moduli. The $\varepsilon_{\mathrm{c}}=0.05$ demonstrated stiffening between the strains 0.05 and 0.1 . In addition, the $\varepsilon_{\mathrm{c}}=0.05$ composites were stiffer than the straight bundle composites for large strains.
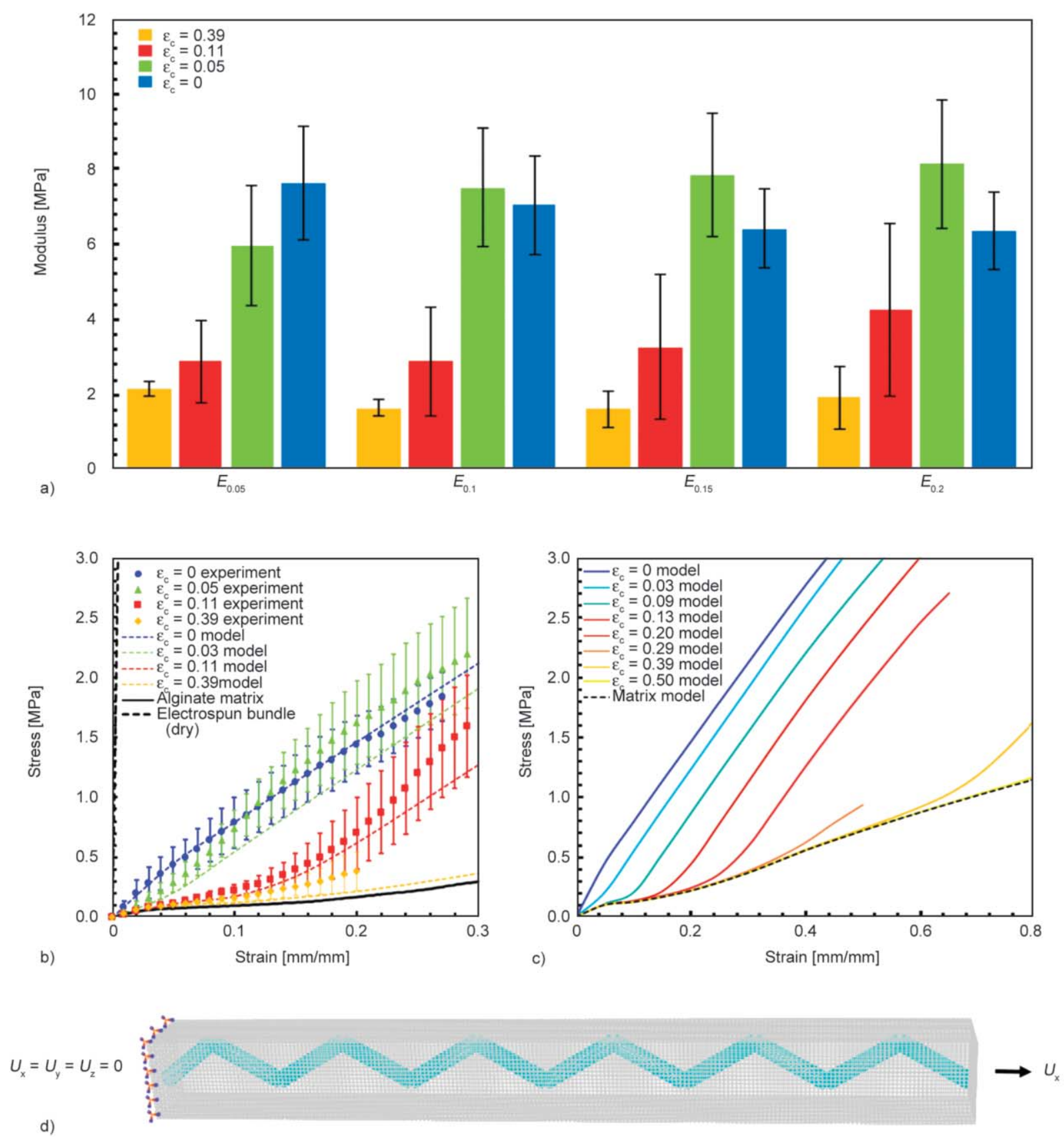

Figure 7. Mechanical behavior of polyamide-alginate soft composites under unidirectional tension. (a) The modulus of composites with a different crimping angle at $0.05,0.1,0.15$, and 0.2 strain. (b) Stress-strain curves for composites with different crimping angles under unidirectional tension, experiments $v s$. FE models. (c) The influence of different crimping angles on the mechanical behavior in FE models of polyamide-alginate composites. (d) polyamidealginate FE model and boundary conditions. 
The FE models (Figure 7d) provided similar results to the experimental behavior for all tested crimping angles. However, the experimental results were slightly stiffer compared with the simulation results (Figure 7b). As shown in Figure 7c, in the additional models with varied crimping degrees, all toe regions followed the matrix behavior. The transition between the matrix and the fiber modes occurred around the $\varepsilon c$ strains. The crimping angle controlled the length of the toe region: when the crimp angle was smaller (and $\varepsilon_{\mathrm{c}}$ was larger), the toe region was larger (Figure $7 \mathrm{~b}, 7 \mathrm{c})$. When the bundle was straight, the behavior was linear; that is, the fiber bundle entirely governed the tensile behavior.

\subsection{Mechanical behavior of dry film and bundle}

The mechanical properties of the bundle were significantly larger than those of the electrospun film $(p \leq 0.0001)$. The ultimate tensile stresses were 193.6 \pm 38.2 and $8.5 \pm 3.3 \mathrm{MPa}$, for the dry bundle $(n=$ $16)$ and film $(n=24)$, respectively. The maximum strains were $0.51 \pm 0.17$ and $0.31 \pm 0.10$ for the dry bundle and film, respectively (Figure 8a, 8b).

\subsection{The mechanical effect of nanocrimping}

The mechanical effect of nanocrimping was first investigated for the dried film and bundle. The differences in the ultimate tensile stresses and maximum strains between the bundle and film with and without nanocrimping were negligible (Figure 8). The nanocrimping effect was observed in the SEM images (Figure 9) but was not uniform. The ultimate tensile stresses of the bundle were $196.2 \pm 38.8 \mathrm{MPa}(n=8)$ and $191 \pm 41.9 \mathrm{MPa}(n=8),(p=0.88)$ with and without nanocrimping, respectively, while the maximum strains were $0.48 \pm 0.16$ and $0.54 \pm 0.17(p=0.5)$ with and without nanocrimping, respectively (Figure 8c, $8 \mathrm{~d})$. The ultimate tensile stresses of the film were 8.8 $\pm 3.4 \mathrm{MPa}(n=16)$ and $8.1 \pm 3.3 \mathrm{MPa}(n=8)(p=$ 0.72 ) with and without nanocrimping, respectively, while the maximum strains were $0.32 \pm 0.1$ and $0.29 \pm 0.09(p=0.24)$ with and without nanocrimping, respectively (Figure 8e, 8f).

Moreover, due to the negligible effect of the nanocrimping on the deformation behavior on the bundle and film, we could not see any difference in the composite behavior with $127^{\circ}$ crimping (higher length-scale): The ultimate tensile stresses were $2.13 \pm 0.95 \mathrm{MPa}(n=11)$ and $2.23 \pm 0.99 \mathrm{MPa}(n=8)$,
( $p=0.2$ ) with and without nanocrimping, respectively, while the maximum strains were $0.41 \pm 0.06$ and $0.35 \pm 0.06(p=0.6)$ with and without nanocrimping, respectively (Figure $8 \mathrm{~g}, 8 \mathrm{~h}$ ).

\section{Discussion}

A new architectural soft biomimetic composite with a hierarchical structure was fabricated from a polyamide bundle embedded in an alginate hydrogel matrix. Polycarpolactam (Nylon 6) is an artificial hydrophilic polyamide, similar to proteins that are naturally occurring polyamides [67]. The composite's design, the hydrophilic fiber bundle, and the hydrated matrix enabled weak hydrophilic non-covalent interactions connecting the bundle and matrix. These interactions, such as hydrogen bonds, are known to be reversible $[11,30,68,69]$, as is also the case for natural soft composites, as soft tissues. Therefore, the loads are gradually transmitted from the matrix to the fibers through the interface. In our material system, the main evidence for creating this interface is the ability of the bundle to significantly reinforce the hydrogel at a very low FVF (Figure 5). In the absence of an interface, gross slipping would occur between the bundle and matrix owing to the substantial differences between their mechanical properties.

In the SEM images, the matrix exhibits good nanofiber coverage (Figure $4 \mathrm{c}, 4 \mathrm{~d}$ ). Although the material failure is by pull-out (i.e., the interface failed), the matrix was significantly reinforced before failure (Figure 5a). The presence of weak interactions at the interface is responsible for the high toughness and large deformations of the material. Similarly, in the interface of natural composites, the interactions between the collagen fibrils and glycosaminoglycans are weak and non-covalent. Therefore, these interactions can easily form and dissociate and enable large-deformation behavior [11, 70-72].

Previous studies have demonstrated the effect of FVF and fiber orientation on the mechanical behavior of soft composites and their impact on mechanical behavior [27-31]. In this study, an FVF of $3 \pm 1.6 \%$ was used as a proof-of-concept to test the effect of other parameters, including the hierarchical structure of the bundle and crimping at different length scales. The bundle was constructed as a rolled electrospun polyamide nanofiber film. The ultimate tensile strength and maximum strain of the electrospun film were 24 and 1.64 times less than the bundle, respectively. An optional explanation for this difference is 

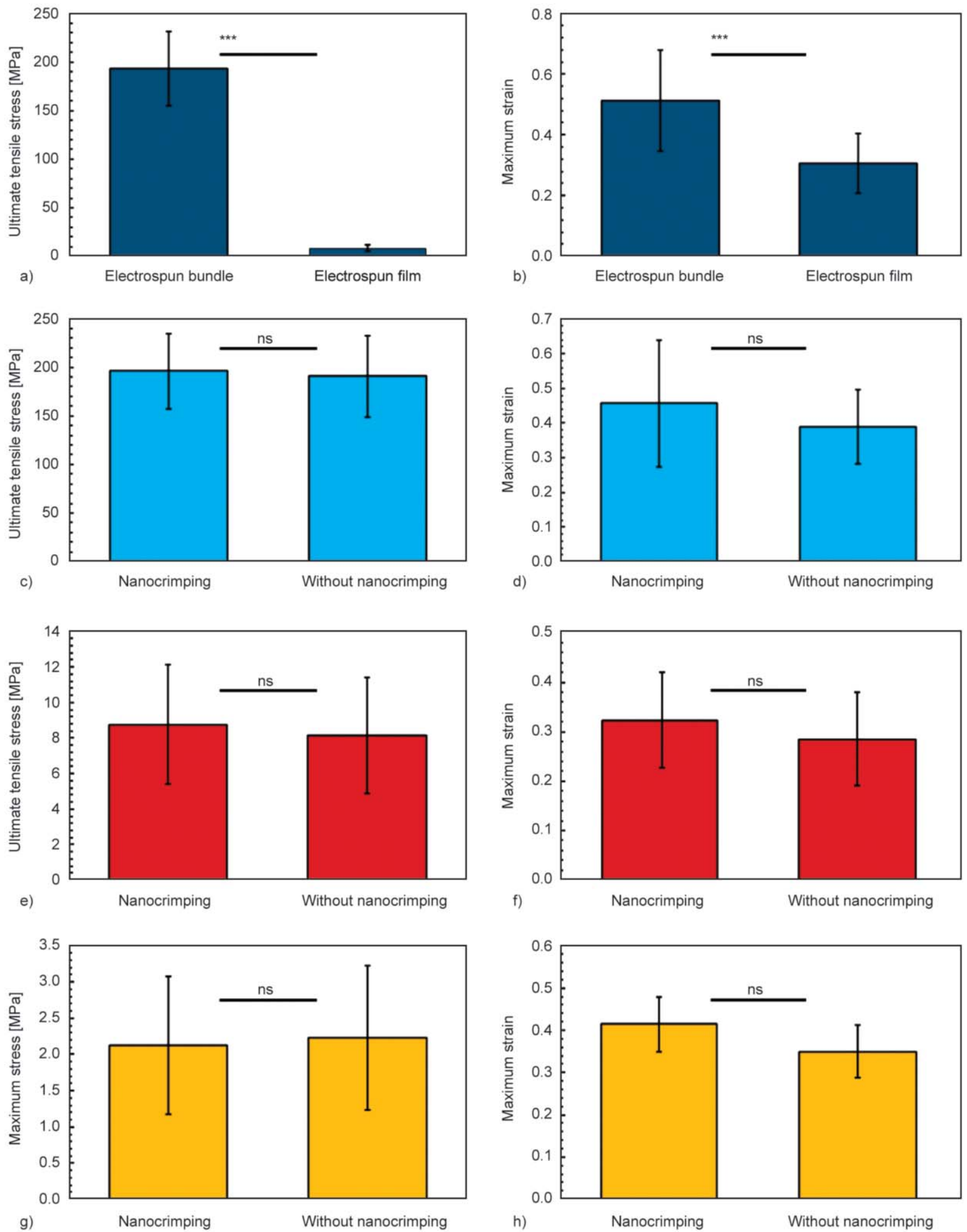

Figure 8. The mechanical properties of dry electrospun bundle and film and the effect of nanocrimping. (a, b) UTS and maximum strain of electrospun bundle $(n=16) v s$. film $(n=24)$. Effect of nanocrimping on the bundle (c, d) (with nanocrimping- $n=8$, w/o nanocrimping- $n=8$ ), film (e, f) (with nanocrimping- $n=16$, w/o nanocrimping- $n=8$ ) and composites $(\mathrm{g}, \mathrm{h})\left(\varepsilon_{\mathrm{c}}=0.11\right.$, with nanocrimping- $n=11$, w/o nanocrimping- $\left.n=8\right)$.

that the film consists of inner defects. These defects are more distinct in the film but have less effect on the bundle form due to its structure. The latter phenomenon is similar to naturally occurring materials, where defects are present at certain hierarchical levels but do not necessarily weaken the material; instead, they make it stronger and tougher $[73,74]$. An additional explanation is that the bundle consists of 

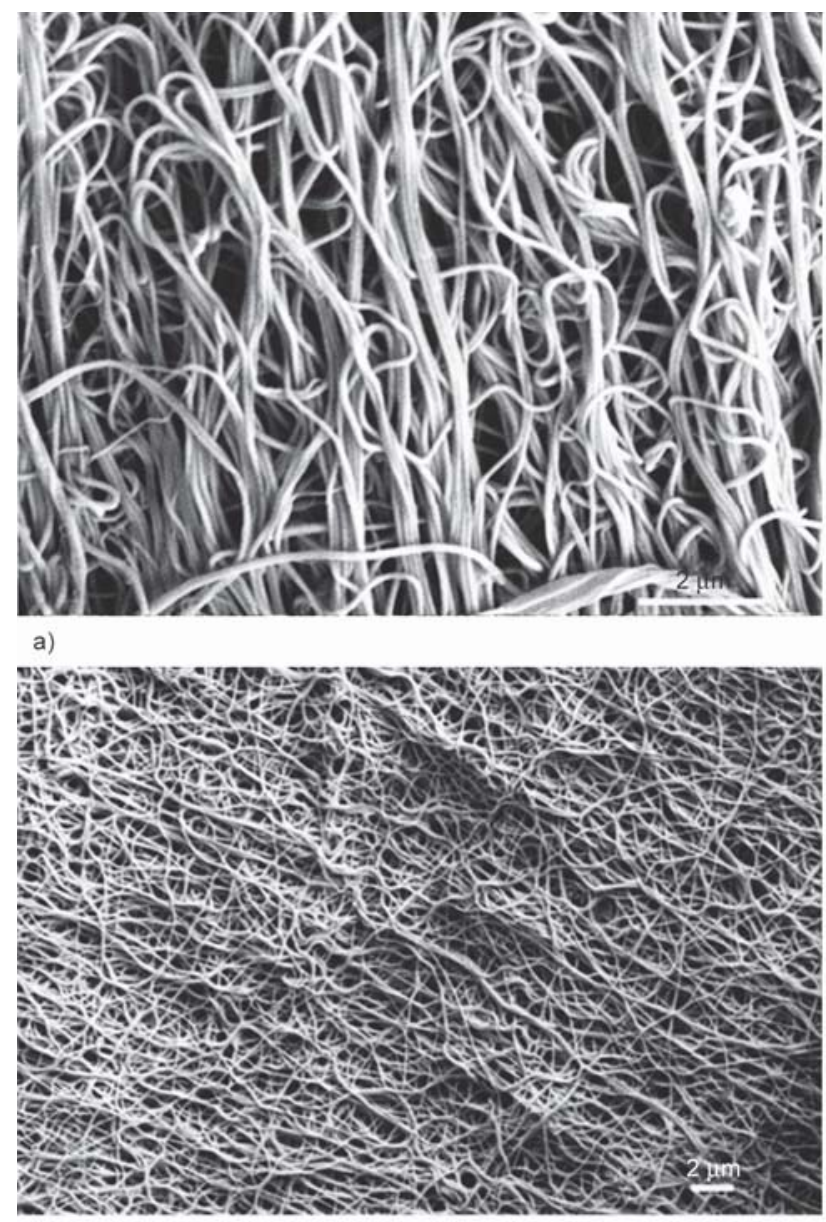

c)

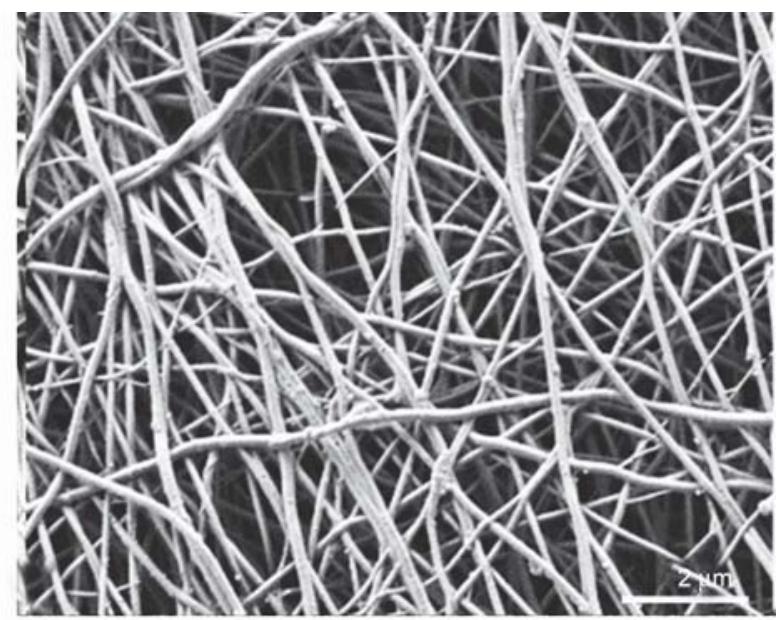

b)

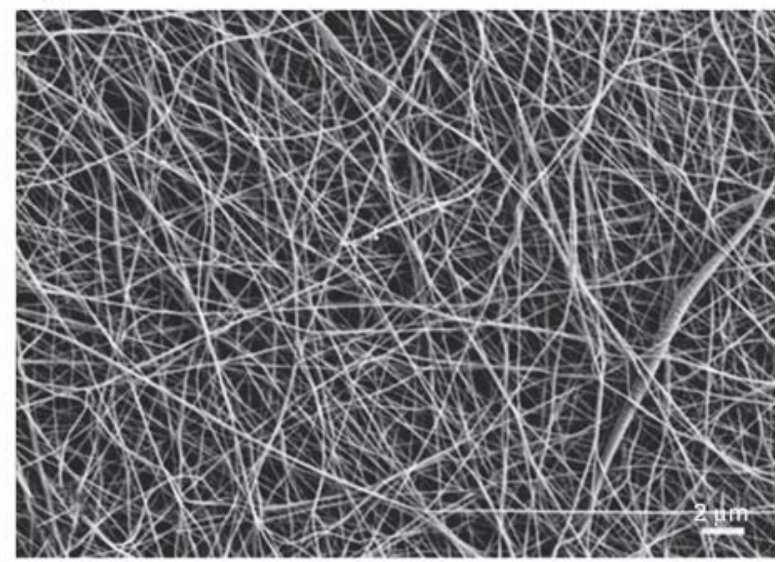

d)

Figure 9. Nanocrimping under SEM. Electrospun film with $(a, c)$ and without $(b, d)$ nanocrimping.

several layers of rolled film with aligned nanofibers. When the bundle is stretched, the film layers are stretched in parallel, the modulus is stiffened, and the deformations decrease compared to the film alone.

The bundle reinforced the alginate hydrogel matrix; however, owing to the low FVF, it was significantly less stiff compared with the electrospun film and bundle. In nature, collagen fibers also exhibit different mechanical behaviors at different length scales, and the molecular scale is the stiffest [11].

The mechanical behavior of the crimped polyamidealginate composite followed a J-shaped nonlinear behavior (Figure $5 \mathrm{~b}$ and 7), which was similar to that of the toe, heel, and linear regions of natural collagenous soft tissues.

It is important to note that the fabrication was done manually to present a proof-of-concept hierarchical soft composite. The manual fabrication, although executed carefully, added a degree of variance to the results. However, the results that are shown demonstrate a clear trend. Moreover, a single-bundle composite is not applicable alone, but in order to simplify the material system, we used a single-bundle composite. Hierarchical multi-bundle composites will be designed and tested in our future studies.

Many structural features and mechanisms affect the mechanical behavior in soft tissues (such as fiber volume fraction, fiber orientation, graded transitions, hierarchy, fiber crimping, weak interfaces, sacrificial cross-bridges, etc.). Thus our ability to define the different mechanical roles for each of these is quite limited. However, by using reverse biomimetics principles [50, 57-59], we can gradually separate the complex structural mechanisms by engineering principles. Since collagen fibers are the main load-bearing component in these tissues [21], it can be argued that uniaxial tension is justified to simplify other structural mechanisms such as reorientation of fibers, for example, for skin tissue [75] and annulus fibrosus $[76,77]$. In soft tissues, the straightening of collagen crimping is known to affect strain stiffening in different tissues such as skin [75], tendon [23], and annulus fibrosus [76]. Under uniaxial loading, the 
crimping of the bundle was gradually decreased by straightening (Figure 5b), and the matrix dominated the mechanical behavior in the toe region. When the bundle was straight, it started carrying the load, which resulted in stiffening in the stress-strain curve. In the toe region of collagenous tissues, collagen crimp straightening was observed using a light microscope $[22,23,78,79]$. Soft tissue crimping was seen in the micro-level scale (crimp length 10-300 $\mu \mathrm{m}$ ) [11,33, $78,80-82]$. For our composite, crimping was observed at the same scale and ranged between 300 $800 \mu \mathrm{m}$. The bundle diameter was $0.25 \pm 0.05 \mathrm{~mm}$, which is the same range as that of the tendon fascicles [11].

The application of different crimping degrees (experimentally and numerically) resulted in a controlled transition between the matrix and the fiber modes. As was expected, the toe region was larger when the crimping angle was smaller (Figure 7). As already mentioned, in soft tissues, the straightening of collagen crimping is known to affect strain stiffening in different tissues such as skin [75], tendon [23], and annulus fibrosus [76]. Different crimping angles characterized different tendons, such as the Patellar and Achilles tendons (knee and foot tendons, respectively), such that the latter crimping angle was smaller than that of the patellar tendon, which allowed for a larger toe region [11, 82]. Moreover, larger toe regions are typically found in tissues with larger elastin content, which allows for a larger toe region and larger deformations (20-30\%) [24, 80].

Although the experimental and simulation results are in good agreement, the experimental results demonstrated stiffer behavior for all crimping angles compared with the model. This stiffer behavior in the model may be attributed to the simplified representation of the bundle in the model, which was assumed to be continuous with a circular cross-section, whereas the bundle structure is, in fact, hierarchical and consists of nanofibers that can stiffen the composite mechanical behavior. However, the similarity implies that the crimping in the millimetric scale governs the deformation behavior, and the initial part of the stress-strain curve is a matrix-dominated region. Although the overall stiffening can be referred to as bundle crimping, the inner hierarchy of the bundle provides additional stiffening that cannot be seen in the simplified model.

Crimping at the nanolevel was also investigated in our polyamide-alginate composite (Figure 8). At the nanoscale, crimping was negligible in the toe region, in the ultimate tensile strength, and the ultimate strain at the bundle and film levels. The insignificant effect of the crimping in the nanoscale may be attributed to the insufficient alignment of fibers. However, an alternative explanation is that crimping at the nanoscale does not affect these properties but may have a synergistic effect on the toughness of the composite, which cannot be isolated from the other effects observed in the overall behavior of the composite. In the polyamide-alginate composite, the nanofibers had a similar diameter to the collagen fibrils (100$300 \mathrm{~nm}$ ). Additionally, they were located in the hydrated surrounding of the hydrogel, which allowed the formation of hydrogen bonds and enabled sliding similar to the native composites. In the linear region of soft tissue, such as a tendon, observation in X-ray synchrotron $[22,23,26]$ revealed that the collagen fibrils $(50-500 \mathrm{~nm})$ are slipping on top of each other, owing to the hydrated proteoglycans matrix. This slipping enables tendon elongation with smaller strains on the fibers' inner structures. Additionally, the hydrated surrounding generated by the matrix contributes to the hydrogen bond formation and sliding and serves as a plasticizer [11, 22, 23, 25, 26, 83, 84].

The failure of the polyamide-alginate composite is complex and influenced by the synergistic effects of several structural mechanisms. Thus, isolating the direct structural motif contributing to the mechanical behavior is challenging since the failure is affected by the cumulative effect of different motifs, as is also the case for soft composite tissues [11], even though our composite is relatively simple.

Soft collagenous tissues are characterized by high toughness and tear resistance [11], for example, skin [75], meniscus [85, 86], and tendon [87, 88]. Several structural mechanisms are involved in this behavior, such as water presence that allows slipping between the fibers and increase elasticity and ductility, the reorientation, crimping straightening and stretching of fibrils, and fiber bridging [11]. In our material system, the weak interface created between the hydrogel matrix and the polyamide bundle, hierarchical bundle structure, applied crimping, the pull-out, and crossbridges (Figure 6) are assembled to allow a considerable tear resistance, similar to soft tissues. Most of the samples failed by bundle pull-out, that is, by the failure of the weak interface between the matrix and the bundle (Figure 6, 6b and 5b). Several structural effects known to occur in natural soft composites 
were also observed in our polyamide-alginate composite. The SEM observation revealed that the bundle pull-out was long (Figure 6a, 6b). This phenomenon has also been observed in various collagenbased natural materials, such as bone and fish scales [11] and CNT-based composites [47, 89], and laser engraved glass structures inspired by the nacre structure [90].

Moreover, and very importantly, the nanoscale reinforcement is known to simultaneously favor the strength and toughness of materials [91, 92]. In our case, the polyamide nanofibers may be recruited and realigned to increase the toughness of the material together with and the creation of cross-bridges with the matrix and within the bundle (Figure 6c, 6d). Similar mechanisms have also been observed in bone tissues at the nanoscale [93, 94], where toughness is governed by the nanoscale interface between matrix and fibers.

\section{Conclusions}

In summary, this study demonstrated a proof-of-concept soft composite material system that mimics various structural motifs such as crimping, hierarchy, and a weak interface, present in natural soft tissues. We tested the influence of these structural motifs on material stiffening, fiber-matrix transition, and toughening. The current study demonstrates the feasibility of mimicking natural structural motifs in a simple synthetic material system and provides a better understanding of the structure-function relationship in biomimetic soft composites. The current results could be significant in designing and developing the next generation of soft architectural composites with tailor-designed mechanical behavior for various applications such as soft robotics, tissue engineering, and biomedical devices.

\section{References}

[1] Wegst U. G., Bai H., Saiz E., Tomsia A. P., Ritchie R. O.: Bioinspired structural materials. Nature Materials, 14, 23-36 (2015). https://doi.org/10.1038/nmat4089

[2] Choi S., Lee H., Ghaffari R., Hyeon T., Kim D-H.: Recent advances in flexible and stretchable bio-electronic devices integrated with nanomaterials. Advanced Materials, 28, 4203-4218 (2016).

https://doi.org/10.1002/adma.201504150
[3] Jang K-I., Chung H. U., Xu S., Lee C. H., Luan H., Jeong J., Cheng H., Kim G-T., Han S. Y., Lee J. W., Kim J., Cho M., Miao F., Yang Y., Jung H. N., Flavin M., Liu H., Kong G. W., Yu K. J., Rhee S. I., Chung J., Kim B., Kwak J. W., Yun M. H., Kim J. Y., Song Y. M., Paik U., Zhang Y., Huang Y., Rogers J. A.: Soft network composite materials with deterministic and bio-inspired designs. Nature Communications, 6, 6566/1-6566/11 (2015).

https://doi.org/10.1038/ncomms7566

[4] Kokkinis D., Bouville F., Studart A. R.: 3D printing of materials with tunable failure via bioinspired mechanical gradients. Advanced Materials, 30, 1705808/11705808/9 (2018). https://doi.org/10.1002/adma.201705808

[5] Ma M., Guo L., Anderson D. G., Langer R.: Bio-inspired polymer composite actuator and generator driven by water gradients. Science, 339, 186-189 (2013). https://doi.org/10.1126/science.1230262

[6] Munch E., Launey M. E., Alsem D. H., Saiz E., Tomsia A. P., Ritchie R. O.: Tough, bio-inspired hybrid materials. Science, 322, 1516-1520 (2008).

https://doi.org/10.1126/science.1164865

[7] Sanchez C., Arribart H., Guille M. M. G.: Biomimetism and bioinspiration as tools for the design of innovative materials and systems. Nature Materials, 4, 277-288 (2005).

https://doi.org/10.1038/nmat1339

[8] Schaffner M., Faber J. A., Pianegonda L., Rühs P. A., Coulter F., Studart A. R.: 3D printing of robotic soft actuators with programmable bioinspired architectures. Nature Communications, 9, 878/1-878/9 (2018). https://doi.org/10.1038/s41467-018-03216-w

[9] Studart A. R.: Towards high-performance bioinspired composites. Advanced Materials, 24, 5024-5044 (2012). https://doi.org/10.1002/adma.201201471

[10] Bar-Cohen Y.: Biomimetics - Using nature to inspire human innovation. Bioinspiration and Biomimetics, 1, P1-P12 (2006). https://doi.org/10.1088/1748-3182/1/1/P01

[11] Yang W., Meyers M. A., Ritchie R. O.: Structural architectures with toughening mechanisms in nature: A review of the materials science of Type-I collagenous materials. Progress in Materials Science, 103, 425-483 (2019). https://doi.org/10.1016/j.pmatsci.2019.01.002

[12] Ritchie R. O.: The conflicts between strength and toughness. Nature Materials, 10, 817-822 (2011). https://doi.org/10.1038/nmat3115

[13] Achrai B., Bar-On B., Wagner H.: Biological armors under impact - Effect of keratin coating, and synthetic bio-inspired analogues. Bioinspiration and Biomimetics, 10, 016009/1-016009/7 (2015). https://doi.org/10.1088/1748-3190/10/1/016009 
[14] Achrai B., Wagner H. D.: The turtle carapace as an optimized multi-scale biological composite armor - A review. Journal of the Mechanical Behavior of Biomedical Materials, 73, 50-67 (2017).

https://doi.org/10.1016/j.jmbbm.2017.02.027

[15] Barthelat F.: Biomimetics for next generation materials. Philosophical Transactions of the Royal Society A: Mathematical, Physical and Engineering Sciences, 365, 2907-2919 (2007).

https://doi.org/10.1098/rsta.2007.0006

[16] Espinosa H. D., Rim J. E., Barthelat F., Buehler M. J.: Merger of structure and material in nacre and bone Perspectives on de novo biomimetic materials. Progress in Materials Science, 54, 1059-1100 (2009).

https://doi.org/10.1016/j.pmatsci.2009.05.001

[17] Ahn S-H., Lee K-T., Kim H-J., Wu R., Kim J-S., Song S-H.: Smart soft composite: An integrated 3D soft morphing structure using bend-twist coupling of anisotropic materials. International Journal of Precision Engineering and Manufacturing, 13, 631-634 (2012).

https://doi.org/10.1007/s12541-012-0081-8

[18] Kim S., Laschi C., Trimmer B.: Soft robotics: A bioinspired evolution in robotics. Trends in Biotechnology, 31, 287-294 (2013).

https://doi.org/10.1016/j.tibtech.2013.03.002

[19] Spackman C. C., Frank C. R., Picha K. C., Samuel J.: 3D printing of fiber-reinforced soft composites: Process study and material characterization. Journal of Manufacturing Processes, 23, 296-305 (2016). https://doi.org/10.1016/j.jmapro.2016.04.006

[20] Meyers M. A., McKittrick J., Chen P-Y.: Structural biological materials: Critical mechanics-materials connections. Science, 339, 773-779 (2013).

https://doi.org/10.1126/science.1220854

[21] Holzapfel G. A.: Biomechanics of soft tissue. in 'The handbook of materials behavior models' (ed.: Lemaitre J.) Academic Press, San Diego, 1049-1063 (2001).

[22] Fratzl P., Weinkamer R.: Nature's hierarchical materials. Progress in Materials Science, 52, 1263-1334 (2007). https://doi.org/10.1016/j.pmatsci.2007.06.001

[23] Fratzl P., Misof K., Zizak I., Rapp G., Amenitsch H., Bernstorff S.: Fibrillar structure and mechanical properties of collagen. Journal of Structural Biology, 122, 119-122 (1998). https://doi.org/10.1006/jsbi.1998.3966

[24] Venkatraman S., Boey F., Lao L. L.: Implanted cardiovascular polymers: Natural, synthetic and bio-inspired. Progress in Polymer Science, 33, 853-874 (2008). https://doi.org/10.1016/j.progpolymsci.2008.07.001

[25] Thorpe C. T., Birch H. L., Clegg P. D., Screen H. R.: The role of the non-collagenous matrix in tendon function. International Journal of Experimental Pathology, 94, 248-259 (2013).

https://doi.org/10.1111/iep.12027
[26] Misof K., Rapp G., Fratzl P.: A new molecular model for collagen elasticity based on synchrotron X-ray scattering evidence. Biophysical Journal, 72, 1376-1381 (1997). https://doi.org/10.1016/S0006-3495(97)78783-6

[27] Caves J. M., Kumar V. A., Martinez A. W., Kim J., Ripberger C. M., Haller C. A., Chaikof E. L.: The use of microfiber composites of elastin-like protein matrix reinforced with synthetic collagen in the design of vascular grafts. Biomaterials, 31, 7175-7182 (2010). https://doi.org/10.1016/j.biomaterials.2010.05.014

[28] Caves J. M., Cui W., Wen J., Kumar V. A., Haller C. A., Chaikof E. L.: Elastin-like protein matrix reinforced with collagen microfibers for soft tissue repair. Biomaterials, 32, 5371-5379 (2011).

https://doi.org/10.1016/j.biomaterials.2011.04.009

[29] Sharabi M., Mandelberg Y., Benayahu D., Benayahu Y., Azem A., Haj-Ali R.: A new class of bio-composite materials of unique collagen fibers. Journal of the Mechanical Behavior of Biomedical Materials, 36, 71-81 (2014). https://doi.org/10.1016/j.jmbbm.2014.04.008

[30] Sharabi M., Benayahu D., Benayahu Y., Isaacs J., Haj-Ali R.: Laminated collagen-fiber bio-composites for soft-tissue bio-mimetics. Composites Science and Technology, 117, 268-276 (2015).

https://doi.org/10.1016/j.compscitech.2015.06.024

[31] Sharabi M., Varssano D., Eliasy R., Benayahu Y., Benayahu D., Haj-Ali R.: Mechanical flexure behavior of bio-inspired collagen-reinforced thin composites. Composite Structures, 153, 392-400 (2016).

https://doi.org/10.1016/j.compstruct.2016.06.031

[32] Gathercole L. J., Keller A.: Crimp morphology in the fibre-forming collagens. Matrix, 11, 214-234 (1991). https://doi.org/10.1016/S0934-8832(11)80161-7

[33] Zhao L., Thambyah A., Broom N.: Crimp morphology in the ovine anterior cruciate ligament. Journal of Anatomy, 226, 278-288 (2015).

https://doi.org/10.1111/joa.12276

[34] de Campos Vidal B.: Image analysis of tendon helical superstructure using interference and polarized light microscopy. Micron, 34, 423-432 (2003).

https://doi.org/10.1016/S0968-4328(03)00039-8

[35] Caves J. M., Kumar V. A., Xu W., Naik N., Allen M. G., Chaikof E. L.: Microcrimped collagen fiber-elastin composites. Advanced Materials, 22, 2041-2044 (2010). https://doi.org/10.1002/adma.200903612

[36] Nunes J. K., Constantin H., Stone H. A.: Microfluidic tailoring of the two-dimensional morphology of crimped microfibers. Soft Matter, 9, 4227-4235 (2013). https://doi.org/10.1039/C3SM27579E

[37] Chen F., Hayami J. W., Amsden B. G.: Electrospun poly(L-lactide-co-acryloyl carbonate) fiber scaffolds with a mechanically stable crimp structure for ligament tissue engineering. Biomacromolecules, 15, 1593-1601 (2014). https://doi.org/10.1021/bm401813j 
[38] Chao P-H. G., Hsu H-Y., Tseng H-Y.: Electrospun microcrimped fibers with nonlinear mechanical properties enhance ligament fibroblast phenotype. Biofabrication, 6, 035008/1-035008/10 (2014). https://doi.org/10.1088/1758-5082/6/3/035008

[39] Naik N., Caves J., Chaikof E. L., Allen M. G.: Generation of spatially aligned collagen fiber networks through microtransfer molding. Advanced Healthcare Materials, 3, 367-374 (2014). https://doi.org/10.1002/adhm.201300112

[40] Liu W., Lipner J., Moran C. H., Feng L., Li X., Thomopoulos S., Xia Y.: Generation of electrospun nanofibers with controllable degrees of crimping through a simple, plasticizer-based treatment. Advanced Materials, 27, 2583-2588 (2015).

https://doi.org/10.1002/adma.201500329

[41] Wu Y., Wu B., Vijayavenkataraman S., Wong Y. S., Fuh J. Y. H.: Crimped fiber with controllable patterns fabricated via electrohydrodynamic jet printing. Materials and Design, 131, 384-393 (2017). https://doi.org/10.1016/j.matdes.2017.06.027

[42] Fleischer S., Feiner R., Shapira A., Ji J., Sui X., Wagner H. D., Dvir T.: Spring-like fibers for cardiac tissue engineering. Biomaterials, 34, 8599-8606 (2013). https://doi.org/10.1016/j.biomaterials.2013.07.054

[43] Huang Z-M., Zhang Y-Z., Kotaki M., Ramakrishna S.: A review on polymer nanofibers by electrospinning and their applications in nanocomposites. Composites Science and Technology, 63, 2223-2253 (2003). https://doi.org/10.1016/S0266-3538(03)00178-7

[44] Teo W. E., Ramakrishna S.: A review on electrospinning design and nanofibre assemblies. Nanotechnology, 17, 89-106 (2006). https://doi.org/10.1088/0957-4484/17/14/R01

[45] Huang X., Wang R., Jiao T., Zou G., Zhan F., Yin J., Zhang L., Zhou J., Peng Q.: Facile preparation of hierarchical AgNP-loaded MXene/ $\mathrm{Fe}_{3} \mathrm{O}_{4} /$ polymer nanocomposites by electrospinning with enhanced catalytic performance for wastewater treatment. ACS Omega, 4, 1897-1906 (2019). https://doi.org/10.1021/acsomega.8b03615

[46] Wang C., Sun S., Zhang L., Yin J., Jiao T., Zhang L., Xu Y., Zhou J., Peng Q.: Facile preparation and catalytic performance characterization of AuNPs-loaded hierarchical electrospun composite fibers by solvent vapor annealing treatment. Colloids and Surfaces A: Physicochemical and Engineering Aspects, 561, 283-291 (2019).

https://doi.org/10.1016/j.colsurfa.2018.11.002

[47] Sui X., Wagner H. D.: Tough nanocomposites: The role of carbon nanotube type. Nano Letters, 9, 1423-1426 (2009).

https://doi.org/10.1021/n1803241y
[48] Sensini A., Gualandi C., Zucchelli A., Boyle L. A., Kao A. P., Reilly G. C., Tozzi G., Cristofolini L., Focarete M. L.: Tendon fascicle-inspired nanofibrous scaffold of polylactic acid/collagen with enhanced 3D-structure and biomechanical properties. Scientific Reports, 8, 17167/1-17167/15 (2018).

https://doi.org/10.1038/s41598-018-35536-8

[49] Sensini A., Gotti C., Belcari J., Zucchelli A., Focarete M. L., Gualandi C., Todaro I., Kao A. P., Tozzi G., Cristofolini L.: Morphologically bioinspired hierarchical nylon 6,6 electrospun assembly recreating the structure and performance of tendons and ligaments. Medical Engineering and Physics, 71, 79-90 (2019).

https://doi.org/10.1016/j.medengphy.2019.06.019

[50] Fratzl P.: Biomimetic materials research: What can we really learn from nature's structural materials? Journal of the Royal Society Interface, 4, 637-642 (2007). https://doi.org/10.1098/rsif.2007.0218

[51] Wilkerson R. P., Gludovatz B., Watts J., Tomsia A. P., Hilmas G. E., Ritchie R. O.: A novel approach to developing biomimetic ('nacre-like') metal-compliantphase (nickel-alumina) ceramics through coextrusion. Advanced Materials, 28, 10061-10067 (2016). https://doi.org/10.1002/adma.201602471

[52] Zhang M., Jiao D., Tan G., Zhang J., Wang S., Wang J., Liu Z., Zhang Z., Ritchie R. O.: Strong, fracture-resistant biomimetic silicon carbide composites with laminated interwoven nanoarchitectures inspired by the crustacean exoskeleton. ACS Applied Nano Materials, 2, 1111-1119 (2019).

https://doi.org/10.1021/acsanm.9b00063

[53] Libonati F., Vergani L.: Understanding the structureproperty relationship in cortical bone to design a biomimetic composite. Composite Structures, 139, 188198 (2016). https://doi.org/10.1016/j.compstruct.2015.12.003

[54] Greenfeld I., Zhang W., Sui X., Wagner H. D.: Intermittent beading in fiber composites. Composites Science and Technology, 160, 21-31 (2018). https://doi.org/10.1016/j.compscitech.2018.03.003

[55] Peng J., Huang C., Cao C., Saiz E., Du Y., Dou S., Tomsia A. P., Wagner H. D., Jiang L., Cheng Q.: Inverse nacrelike epoxy-graphene layered nanocomposites with integration of high toughness and self-monitoring. Matter, 2, 220-232 (2020). https://doi.org/10.1016/j.matt.2019.08.013

[56] Espinosa H. D., Juster A. L., Latourte F. J., Loh O. Y., Gregoire D., Zavattieri P. D.: Tablet-level origin of toughening in abalone shells and translation to synthetic composite materials. Nature Communications, 2, 173/1173/9 (2011). https://doi.org/10.1038/ncomms 1172

[57] Csete M. E., Doyle J. C.: Reverse engineering of biological complexity. Science, 295, 1664-1669 (2002). https://doi.org/10.1126/science.1069981 
[58] Vincent J. F.: Biomimetic modelling. Philosophical Transactions of the Royal Society of London Series B: Biological Sciences, 358, 1597-1603 (2003). https://doi.org/10.1098/rstb.2003.1349

[59] Wilson J. O., Rosen D.: Systematic reverse engineering of biological systems. in 'ASME 2007 International Design Engineering Technical Conferences and Computers and Information in Engineering Conference' Las Vegas, USA, 69-78 (2009).

https://doi.org/10.1115/DETC2007-35395

[60] Bas O., De-Juan-Pardo E. M., Meinert C., D’Angella D., Baldwin J. G., Bray L. J., Wellard R. M., Kollmannsberger S., Rank E., Werner C.: Biofabricated soft network composites for cartilage tissue engineering. Biofabrication, 9, 025014/1-025014/15 (2017). https://doi.org/10.1088/1758-5090/aa6b15

[61] Benayahu D., Sharabi M., Pomeraniec L., Awad L., Haj-Ali R., Benayahu Y.: Unique collagen fibers for biomedical applications. Marine Drugs, 16, 102/1102/11 (2018).

https://doi.org/10.3390/md16040102

[62] Sharabi M., Wertheimer S., Wade K. R., Galbusera F., Benayahu D., Wilke H-J., Haj-Ali R.: Towards intervertebral disc engineering: Bio-mimetics of form and function of the annulus fibrosus lamellae. Journal of the Mechanical Behavior of Biomedical Materials, 94, 298 307 (2019).

https://doi.org/10.1016/j.jmbbm.2019.03.023

[63] Püspöki Z., Storath M., Sage D., Unser M.: Transforms and operators for directional bioimage analysis: A survey. in 'Focus on bio-image informatics' (eds.: de Vos W., Munck S., Timmermans J. P.) Springer, Cham, 6993 (2016).

https://doi.org/10.1007/978-3-319-28549-8 3

[64] Hotaling N. A., Bharti K., Kriel H., Simon C. G.: DiameterJ: A validated open source nanofiber diameter measurement tool. Biomaterials, 61, 327-338 (2015). https://doi.org/10.1016/j.biomaterials.2015.05.015

[65] Marlow R.: A general first-invariant hyperelastic constitutive model. in 'Constitutive Models for Rubber Conference. London, UK' 157-160 (2003).

[66] Ogden R. W.: Large deformation isotropic elasticity On the correlation of theory and experiment for incompressible rubberlike solids. Proceedings of the Royal Society A, 326, 565-584 (1972). https://doi.org/10.1098/rspa.1972.0026

[67] Gonsalves K. E., Mungara P. M.: Synthesis and properties of degradable polyamides and related polymers. Trends in Polymer Science, 1, 25-31 (1996).

[68] Roldan L. G., Kaufman H. S.: Crystallization of nylon 6. Journal of Polymer Science Part B: Polymer Letters, 1, 603-608 (1963). https://doi.org/10.1002/pol.1963.110011107

[69] Wojtecki R. J., Meador M. A., Rowan S. J.: Using the dynamic bond to access macroscopically responsive structurally dynamic polymers. Nature Materials, 10, 14-27 (2011).

https://doi.org/10.1038/nmat2891
[70] Cribb A., Scott J.: Tendon response to tensile stress: An ultrastructural investigation of collagen:proteoglycan interactions in stressed tendon. Journal of Anatomy, 187, 423-428 (1995).

[71] Scott J. E.: Proteoglycan-fibrillar collagen interactions. Biochemical Journal, 252, 313-323 (1988). https://doi.org/10.1042/bj2520313

[72] Scott J. E.: Extracellular matrix, supramolecular organisation and shape. Journal of Anatomy, 187, 259-269 (1995).

[73] Hughes M.: Defects in natural fibres: Their origin, characteristics and implications for natural fibre-reinforced composites. Journal of Materials Science, 47, 599-609 (2012). https://doi.org/10.1007/s10853-011-6025-3

[74] Gao H., Ji B., Jäger I. L., Arzt E., Fratzl P.: Materials become insensitive to flaws at nanoscale: Lessons from nature. Proceedings of the national Academy of Sciences, 100, 5597-5600 (2003). https://doi.org/10.1073/pnas.0631609100

[75] Yang W., Sherman V. R., Gludovatz B., Schaible E., Stewart P., Ritchie R. O., Meyers M. A.: On the tear resistance of skin. Nature Communications, 6, 6649/16649/10 (2015). https://doi.org/10.1038/ncomms7649

[76] Sharabi M., Wade K., Haj-Ali R.: The mechanical role of collagen fibers in the intervertebral disc. in 'Biomechanics of the spine' (eds.: Galbusera F., Wilke H-J.) Elsevier, London, 105-123 (2018).

https://doi.org/10.1016/B978-0-12-812851-0.00007-0

[77] Cassidy J., Hiltner A., Baer E.: Hierarchical structure of the intervertebral disc. Connective Tissue Research, 23, 75-88 (1989). https://doi.org/10.3109/03008208909103905

[78] Diamant J., Keller A., Baer E., Litt M., Arridge R.: Collagen; Ultrastructure and its relation to mechanical properties as a function of ageing. Proceedings of the Royal Society Series B, 180, 293-315 (1972). https://doi.org/10.1098/rspb.1972.0019

[79] Abrahams M.: Mechanical behaviour of tendon in vitro. Medical and Biological Engineering, 5, 433-443 (1967). https://doi.org/10.1007/BF02479137

[80] Holzapfel G. A.: Collagen in arterial walls: Biomechanical aspects. in 'Collagen' (ed.: Fratzl P.) Springer, Boston, 285-324 (2008). https://doi.org/10.1007/978-0-387-73906-9 11

[81] Rezakhaniha R., Agianniotis A., Schrauwen J. T. C., Griffa A., Sage D., Bouten C. V. C., van de Vosse F. N., Unser M., Stergiopulos N.: Experimental investigation of collagen waviness and orientation in the arterial adventitia using confocal laser scanning microscopy. Biomechanics and Modeling in Mechanobiology, 11, 461473 (2012). https://doi.org/10.1007/s10237-011-0325-z 
[82] Amiel D., Frank C., Harwood F., Fronek J., Akeson W.: Tendons and ligaments: A morphological and biochemical comparison. Journal of Orthopaedic Research, 1, 257-265 (1983).

https://doi.org/10.1002/jor.1100010305

[83] Fratzl P.: Cellulose and collagen: From fibres to tissues. Current Opinion in Colloid and Interface Science, 8 , 32-39 (2003). https://doi.org/10.1016/S1359-0294(03)00011-6

[84] Yang W., Gludovatz B., Zimmermann E. A., Bale H. A., Ritchie R. O., Meyers M. A.: Structure and fracture resistance of alligator gar (Atractosteus spatula) armored fish scales. Acta Biomaterialia, 9, 5876-5889 (2013). https://doi.org/10.1016/j.actbio.2012.12.026

[85] Bedi A., Kelly N. H., Baad M., Fox A. J. S., Brophy R. H., Warren R. F., Maher S. A.: Dynamic contact mechanics of the medial meniscus as a function of radial tear, repair, and partial meniscectomy. The Journal of Bone and Joint Surgery, 92, 1398-1408 (2010).

https://doi.org/10.2106/JBJS.I.00539

[86] Bansal S., Mandalapu S., Aeppli C., Qu F., Szczesny S. E., Mauck R. L., Zgonis M. H.: Mechanical function near defects in an aligned nanofiber composite is preserved by inclusion of disorganized layers: Insight into meniscus structure and function. Acta Biomaterialia, 56, 102-109 (2017). https://doi.org/10.1016/j.actbio.2017.01.074

[87] Masic A., Bertinetti L., Schuetz R., Galvis L., Timofeeva N., Dunlop J. W., Seto J., Hartmann M. A., Fratzl P.: Observations of multiscale, stress-induced changes of collagen orientation in tendon by polarized Raman spectroscopy. Biomacromolecules, 12, 3989-3996 (2011). https://doi.org/10.1021/bm201008b
[88] Sasaki N., Odajima S.: Elongation mechanism of collagen fibrils and force-strain relations of tendon at each level of structural hierarchy. Journal of Biomechanics, 29, 1131-1136 (1996). https://doi.org/10.1016/0021-9290(96)00024-3

[89] Sui X-M., Giordani S., Prato M., Wagner H. D.: Effect of carbon nanotube surface modification on dispersion and structural properties of electrospun fibers. Applied Physics Letters, 95, 233113/1-233113/3 (2009). https://doi.org/10.1063/1.3272012

[90] Valashani S. M. M., Barthelat F.: A laser-engraved glass duplicating the structure, mechanics and performance of natural nacre. Bioinspiration and Biomimetics, 10, 026005/1-026005/11 (2015). https://doi.org/10.1088/1748-3190/10/2/026005

[91] Evans A. G.: Perspective on the development of hightoughness ceramics. Journal of the American Ceramic Society, 73, 187-206 (1990). https://doi.org/10.1111/j.1151-2916.1990.tb06493.x

[92] Launey M. E., Ritchie R. O.: On the fracture toughness of advanced materials. Advanced Materials, 21, 21032110 (2009). https://doi.org/10.1002/adma.200803322

[93] Gupta H. S., Wagermaier W., Zickler G. A., Aroush D. R-B., Funari S. S., Roschger P., Wagner H. D., Fratzl P.: Nanoscale deformation mechanisms in bone. Nano Letters, 5, 2108-2111 (2005). https://doi.org/10.1021/n1051584b

[94] Gupta H. S., Wagermaier W., Zickler G. A., Hartmann J., Funari S. S., Roschger P., Wagner H. D., Fratzl P.: Fibrillar level fracture in bone beyond the yield point. International Journal of Fracture, 139, 425-436 (2006). https://doi.org/10.1007/s10704-006-6635-y 